\title{
Observation of Noncovalent Complexes to the Avidin Tetramer by Electrospray Ionization Mass Spectrometry
}

\author{
Brenda L. Schwartz, Karen J. Light-Wahl, and Richard D. Smith \\ Chemical Methods and Separations Group, Chemical Sciences Department, Pacific Northwest Laboratory, \\ Richland, Washington, USA
}

\begin{abstract}
Intact avidin-biotin and avidin-biotin maleimide noncovalent complexes have been observed by electrospray ionization mass spectrometry (ESI-MS) by using an extended mass range quadrupole mass spectrometer. By utilizing mild ESI interface conditions, the expected solution behavior of four biotin or biotin maleimide molecules noncovalently binding to each avidin tetramer can be preserved in the gas phase. The ESI-MS results show the appropriate mass additions of $973 \pm 60 \mathrm{Da}$ for biotin and $1802 \pm 40 \mathrm{Da}$ for biotin maleimide to the avidin tetramer species. These results support the hypothesis that substantial retention of higher order structure is possible in the gas phase by using gentle ESI conditions. (J Am Soc Mass Spectrom 1994, 5, 201-204)
\end{abstract}

$\mathrm{E}$ lectrospray ionization mass spectrometry (ESIMS) $[1,2]$ is becoming a useful method for the investigation of molecules that form noncovalent complexes in solution. Weak associations of molecules in solution, such as enzyme-substrate, receptor-ligand, host-guest, and protein-nucleic acid interactions have been demonstrated to survive transfer into the gas phase by ESI [3]. Through the careful control of mass spectrometric interface conditions, noncovalent complexes can be detected and studied by ESI-MS. Unresolved issues regarding the range of applicability of the technique include determining factors that ensure the preservation of these complexes as well as for measuring complex stabilities in the gas phase relative to those in solution.

One of the most well-known and strongest proteinligand interactions found in nature is the avidin-biotin complex. This highly selective noncovalent complexation has had wide applicability in biochemistry, immunochemistry, and affinity chemistry by virtue of its low dissociation constant $\left(K_{\mathrm{D}} \sim 10^{-15} \mathrm{M}\right)$ [4]. Avidin $\left(M_{r} \sim 64,000\right)$ is a glycoprotein found in egg white, and its quaternary structure is a noncovalent tetramer composed of four identical subunits which associate into the active form $[5,6]$. Each subunit contains a 128-residue polypeptide chain with a carbohydrate moiety attached to the asparagine residue at position 17. In addition, each subunit can accommodate one

Address reprint requests to Richard D. Smith, Chemical Methods and Separations Group, Chemical Sciences Department, Pacific Northwest Laboratory. P. O. Box 999, Mail Stop P8-19, Richland, WA 99352. biotin molecule $\left(\mathrm{M}_{\mathrm{r}}=244 \mathrm{Da}\right)$; consequently, the tetrameric form of avidin is capable of noncovalently binding four biotins. In fact, the binding of biotin occurs at sites partially defined by the quaternary structure of the tetramer and involves a number of aromatic and polar interactions [7]. Characterization of the various glycoforms of the individual subunits of avidin has been conducted by ESI-MS [8], but the intact quaternary structure has not been detected within the mass-to-charge ratio range of conventional quadrupole instrumentation. Protein binding studies involving avidin and various biotin derivatives have been performed using microdialysis with ESI-MS [9], but with only indirect evidence of the ability to measure the interaction of the two species in solution. Only recently has the intact avidin tetramer been observed by ESI-MS [10].

For ESI mass analysis, the limitations of commercially available quadrupoles with mass-to-charge ratio ranges commonly less than $\sim 3000$ have been previously noted [11]. To obtain positive ion ESI mass spectra for large proteins, samples are typically placed in an acidic solution to promote sufficient charging of the basic residues in the gas phase so that ions can be detected at lower mass-to-charge ratios. However, experiments performed in our laboratory on a Sciex (Thornhill, Ontario) TAGA 6000E triple quadrupole instrument (mass-to-charge ratio limit 1400) for avidin in acidic solution have been unsuccessful in detecting the tetramer species. Consistent with previous studies [8], only ions corresponding to the individual subunits have been observed within the typically limited mass- 
to-charge ratio range (data not shown). Electrospraying water or ammonium acetate solutions of avidin, where the tetrameric form predominates in solution, has provided mass spectra which are dominated by the intact tetramer. However, the limited amount of charging on the protein possibly due to this more compact solution structure has made the use of an extended mass-tocharge ratio range instrument $(>3000)$ essential for the observation of the active form of avidin, and thereby, the avidin-biotin complex. The present study resolves the question as to why the strong avidin-biotin complex has not been previously observed by ESIMS, shows that the 1:4 avidin-biotin tetrameric complex can be observed under appropriate conditions, and further supports the potential of ESI-MS as a broadly useful technique for the study of noncovalent associations in solution.

\section{Experimental}

All experiments were conducted on a low frequency extended mass-to-charge ratio range $(\sim 45,000)$ quadrupole mass spectrometer developed in our laboratory and described elsewhere [11]. A Tecknivent (St. Louis, MO) Vector One data system was used for data acquisition, which allows a five mass-to-charge ratio window as the smallest step size for this large mass range. Spectra were acquired from $\mathrm{m} / z 500$ to 10,000 , corresponding to approximately 2 minutes per scan, with the accumulation of five averaged scans. The mass-to-charge ratio calibration was performed with horse heart cytochrome $c$ in $\mathrm{pH} 6.7,10 \mathrm{mM}$ ammonium acetate using the $12+$ to $1+$ charge states. The typical resolving power for this quadrupole operated at low frequency is $\sim 50$.

The ESI interface consists of a resistively heated stainless steel capillary $(1 / 16-i n$. nominal o.d., $0.5-\mathrm{mm}$ i.d., $20-\mathrm{cm}$ long) similar to the design of Chait and co-workers [12] and others [13]. Important interface conditions include the extent of resistive capillary heating (reported as watts and the approximate temperature as measured on the outside surface of the capillary), and the voltage offset between the capillary and skimmer lens ( $\triangle C S$ ). A heated countercurrent flow of $\mathrm{N}_{2}$ gas was employed to assist electrospray desolvation. The ESI source used a coaxial flow of $\mathrm{SF}_{6}$ gas for electrospray stabilization. The sample flow rate was 0.5 $\mu \mathrm{L} \min ^{-1}$.

Samples were purchased from Sigma Chemical Co. (St. Louis, MO) and used without further purification. Sample concentrations were $1 \mu \mathrm{g} \mu \mathrm{L}^{-1}$ in $10 \mathrm{mM}$ ammonium acetate ( $\mathrm{pH}$ 8.4). Formation of the complexes in solution was achieved by combining equal volumes of the $1 \mu \mathrm{g} \mu \mathrm{L}^{-1}$ stock solutions of each of the two species, corresponding to approximate molar ratios of 1:260 and 1:140 for avidin:biotin and avidin:biotin maleimide, respectively. Samples were then analyzed following incubation at room temperature for a few hours to ensure complete complexation.

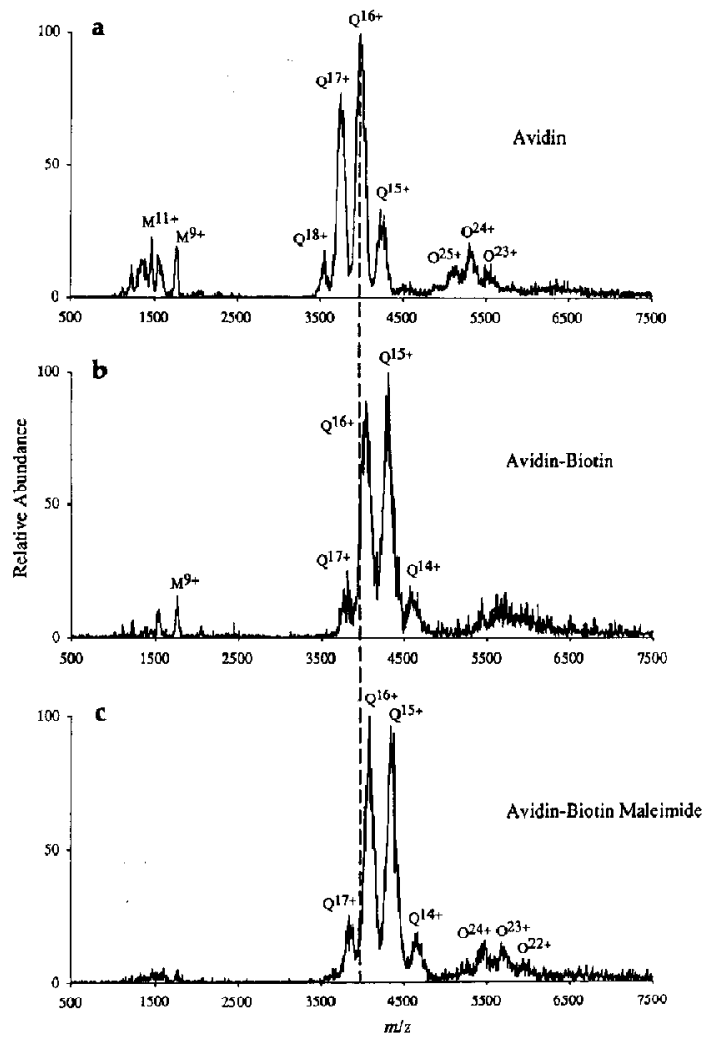

Figure 1. Positive ion ESI mass spectra obtained for (a) egg white avidin, (b) the avidin-biotin complex, and (c) the avidinbiotin maleimide complex. All samples were prepared in $\mathrm{pH} 8.4$, $10 \mathrm{mM}$ ammonium acetate, and ESI spectra were acquired with a heating of 20 watts applied to the metal inlet capillary $\left(\sim 227^{\circ} \mathrm{C}\right.$ ) and a $\triangle C S-80$ volts. The dashed line drawn through the center of the $\mathrm{Q}^{16+}$ ion for the avidin tetramer indicates the observed mass-to-charge ratio shifts for the biotin complexes to avidin.

\section{Results and Discussion}

The ESI mass spectrum of avidin in a $10 \mathrm{mM}$ ammonium acetate solution obtained by using a capillary heat of 20 watts $\left(\sim 227{ }^{\circ} \mathrm{C}\right)$ and a $\Delta \mathrm{CS}$ of 80 volts shows prominent ions for the intact tetramer $\left(Q^{18+}\right.$ to $\mathrm{Q}^{15+}$ ) (Figure 1a). The $\mathrm{M}_{\mathrm{r}}$ of $63,915 \pm 70 \mathrm{Da}$ determined from the experimental data from the four charge states correlates well with the expected $M_{r}$ of 63,870 $\mathrm{Da}$, considering likely contributions from adduction under the relatively mild interface conditions. The interface conditions utilized (heat applied to the metal inlet capillary and $\triangle C S$ ) represented a balance between the desire for the preservation of the intact tetramer as well as adequate desolvation. The center of the tetramer ion distribution at $m / z \sim 4000$ demonstrates the advantage of an extended mass-to-charge ratio capability for detecting the active form of avidin. In addition, peaks resulting from a small amount of aggregation of the avidin tetramers (either in solution or 
by the electrospray process) to form octamers (i.e., the dimer of the tetramer) are observed at even higher mass-to-charge ratios, centered at the peak labeled $\mathrm{O}^{24+}(\mathrm{m} / \mathrm{z}$ 5325). At much lower mass-to-charge ratios weak monomer peaks (labeled $\mathrm{M}^{\mathrm{n}+}$ ) are also evident.

Figure $1 \mathrm{~b}$ illustrates that under similar interface conditions employed for avidin, solutions containing avidin and biotin produce dominant peaks indicative of the 1:4 avidin-biotin tetramer complex. The $M_{r}$ of the complex corresponds to the appropriate mass addition of $973 \pm 60 \mathrm{Da}$, indicating four biotin molecules noncovalently binding to the quaternary structure of avidin. Further evidence of biotin attachment to avidin is given by the apparent shift to higher mass-to-charge ratio of the octamer ion distribution. However, the low resolution of this instrument, likely extensive adduction, and weak signal limit the $\mathrm{M}_{\mathrm{r}}$ precision for the octamer species. Interestingly, we also observe that the complex charge state is shifted to one lower charge on average, that is, to a higher mass-to-charge ratio compared to the avidin tetramer.

Further support for the ability to observe noncovalent complexes to avidin by ESI-MS is shown in Figure 1c for the complex with biotin maleimide, $M_{T}=451$ $\mathrm{Da}$, a biotin derivative which can be used as a thiolspecific probe [14]. Because this derivative is of greater molecular weight than biotin, the apparent mass-tocharge ratio shift for the avidin-biotin maleimide complex is proportionally greater. With the same interface conditions as used to obtain Figure $1 a$ and $b$, the experimentally determined $M_{r}$ for the avidin-biotin maleimide complex corresponds to a shift in mass of $1802 \pm 40 \mathrm{Da}$, confirming that four molecules bind to avidin, as expected. Also, the charge-state distribution shifts lower by one charge state, analogous to the ESI-MS behavior of the avidin-biotin complex. Another important observation is that the ions characteristic of the avidin octamer appear to shift in mass and charge state with an $\mathrm{M}_{\mathrm{r}}$ determination corresponding to approximately eight bound biotin maleimide molecules, consistent with the expected 1:1 stoichiometry.

\section{Conclusions}

Comparison of the mass-to-charge ratio values for the ions of the avidin tetramer to those observed for the avidin-biotin and avidin-biotin maleimide tetramer complexes are consistent with the known solution behavior for one biotin, or its derivative, noncovalently attached to each of the four subunits of avidin. Mass shifts of $973 \pm 60 \mathrm{Da}$ for biotin and $1802 \pm 40 \mathrm{Da}$ for biotin maleimide are observed by ESI-MS, corresponding to the binding of four ligand molecules within experimental uncertainty. Both biotin complexes exhibit a small but reproducible charge-state shift to higher mass-to-charge ratios compared to the avidin tetramer, suggesting that an average of one charge site on avidin is partially hindered upon noncovalent binding of either biotin or its derivative to the protein.
Interestingly, it is known that the binding of biotin actually strengthens and more tightly constrains a portion of the avidin tertiary structure [6]. We suspect this is related to the lower charging observed upon biotin attachment, because it is increasingly apparent that increased structural constraints upon macromolecules serve to reduce both the distribution of charge states as well as the extent of charging by the ESI process.

In addition to the need for an extended mass-tocharge ratio range, careful manipulation of the inlet capillary heating is required to observe these noncovalent complexes by ESI-MS because the avidin tetramer itself is a noncovalent association of four subunits. By utilizing more severe interface conditions, additional thermal or collisional energy can be imparted into these molecules. Through increasing either the heating applied to the metal capillary or the capillary-skimmer offset voltage, dissociation of these noncovalent tetramers into the individual subunits can be readily achieved [3i]. Consistent with previous studies, it is clear that to observe noncovalent complexes by ESI-MS, there is a tradeoff between providing sufficient desolvation to obtain the necessary signal intensities and mass resolution, and interface conditions that are also mild enough to ensure detection of the intact complex. Finally, we note that the observation of the intact complexes with avidin provides further indirect evidence that a considerable portion of the quaternary structure of these complexes may be transferred and maintained intact in the gas phase.

\section{Acknowledgments}

We thank the Laboratory Directed Research and Development of Pacific Nortlwwest Laboratury for support of this research through the U.S. Department of Energy. Pacific Northwest Laboratory is operated by Battelle Memorial Institute for the U.S. Department of Energy, through contract DE-AC06-76RLO 1830. We also thank Drs. David C. Gale and Scott L. Delinger for helpful comments and suggestions.

\section{References}

1. Meng, C. K.; Mann, M.; Fenn, J. B. Z. Phys. D. 1988, 10, 361.

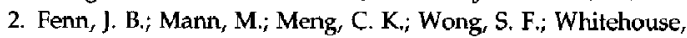
C. M. Mass Spectrom. Reo. 1990, 9, 37.

3. (a) Ganem, B.; Li, Y. T.; Henion, J. J. Am. Chem. Soc. 1991, 113, 6294; (b) Ganem, B.; Li, Y.-T.; Henion, J. J. Am. Chem. Soc. 1991, 113, 7818; (c) Katta, V.; Chait, B. T. J. Am. Chem. Soc. 1991, 113, 8534; (d) Baca, M.; Kent, S. B. H. I. Am. Chem. Soc. 1992, 114, 3992; (e) Ganguly, A. K.; Pramanik, B. N.; Tsarbopoulos, A,; Covey, T. R.; Huang, E.; Fuhrman, S. A. J. Am. Chem. Soc. 1992, 114, 6559; (f) Smith, R. D.; Light-Wahl, K. J.; Winger, B. E.; Loo, J. A. Org. Mass Spectrom. 1992, 27, 811; (g) Jaquinod, M.; Leize, E.; Potier, N.; Albrecht, A.-M.; Shanzer, A.; Van Dorsselaer, A. Tetrahedron Lett. 1993, 34, 2771; (h) Ganem, B.; Henion, J. D. Chem Tracts-Org. Chem. 1993, 6, 1; (i) Smith, R. D.; Light-Wahl, K. J. Biol. Mass Spectrom. 1993, 22, 493; (j) Huang, E. C.; Pramanik, B. N.; Tsarbopottlos, A.; Reichert, P,; Ganguly, A. K.; Trotta, P. P.; Nagabhushan, T. L.; Covey, T. R. J. Am. Soc. Mass Spectrom. 
1993, 4, 624; (k) Li, Y.-T.; Hsieh, Y.-L.; Henion, J. D.; Ganem, B. J. Am. Soc. Masss Spectrom. 1993, 4, 631.

4. Bayer, E. A.; Wilchek, M. Methods of Biochemical Analysis $1980,26,1$.

5. DeLange, R. J.; Huang, T.-S. J. Biol. Chem. 1971, 246, 698.

6. Green, N. M. Advan. Pratein Chem. 1975, $29,85$.

7. Livnah, O.; Bayer, E. A.; Wilchek, M.; Sussman, J. L. Proc. Natl. Acad. Sci. USA 1993, 90, 5076.

8. Smith, P. B.; Snyder, A. P.; Simmons, T. A.; Vestling, M. M. Prucetilnys of the 41st ASMS Conference on Muss Specirometry and Allied Topics; San Francisco, CA, May 30-June 4, 1993; P $76 a$.

9. Kerns; E. H.; Klohr, S. E.; Volk, K. J.; Lee. M. S. Proceedings of the 41st ASMS Conference on Mass Spectrometry and Allied Topics; San Francisco, CA, May 30-June 4, 1993; p 42a.

10. Light-Wahl, K. J.; Schwartz, B. L.; Smith, R. D., unpublished results.

11. Winger, B. E.; Light-Wahl, K. J.; Ogorzalek Loo, R. R.; Udseth, H. R.; Smith, R. D. I. Am. Soc. Mass Spectrom. 1993, 4, 536.

12. Chowdhury, S. K.; Katta, V.; Chait, B. T.; Rapid Commun. Mass Spectrom. 1990, 4, 81.

13. Rockwood, A. L.; Busman, M.; Udseth, H. R.; Smith, R. D. Rapid Commun. Mass Spectrom. 1991, 5, 582.

14. Bayer, E. A.; Zalis, M. G.; Wilchek, M. Arial. Biochem. 1985, 149. 529. 